\title{
REPENSANDO LA CONSTITUCIÓN: UNA MIRADA AL DEBER DE TRABAJAR Y AL DERECHO AL TRABAJO
}

JUANA MARÍA GIL RUIZ 
SUMARIO

1. LA CONSTITUCIÓN DE 1978 ANTE LOS NUEVOS IMPULSOS JURÍDICOS INTERNACIONALES. 2. LA PROTECCIÓN EUROPEA Y NACIONAL POR RAZÓN DE GÉNERO: UNA MIRADA AL DERECHO AL TRABAJO. 3. LA PERSISTENCIA DE LA BRECHA DE GÉNERO Y LA URGENCIA DE UNA RESPUESTA CONSTITUCIONAL. 4. ALGUNAS PROPUESTAS CONCLUYENTES Y DE MEJORA JURÍDICA Y POLÍTICA. 


\title{
REPENSANDO LA CONSTITUCIÓN: UNA MIRADA AL DEBER DE TRABAJAR Y AL DERECHO AL TRABAJO
}

\author{
JUANA MARÍA GIL RUIZ \\ Catedrática de Filosofía del Derecho \\ Universidad de Granada
}

\section{LA CONSTITUCIÓN DE 1978 ANTE LOS NUEVOS IMPULSOS JURÍDICOS INTERNACIONALES}

El 27 de diciembre de 1978, la Constitución española abrió la puerta formal de la igualdad con un novedoso y deseado artículo 14 que proclamaba que «Los españoles son iguales ante la ley, sin que pueda prevalecer discriminación alguna por razón de nacimiento, raza, sexo, religión, opinión o cualquier otra condición o circunstancia personal o social». Probablemente consciente de que un mero principio programático no iba a generar de manera automática la tan anhelada igualdad real, el legislativo constitucional compromete —en el artículo 9.2 C.E. - a los poderes públicos en la lucha por promover las condiciones para que la libertad y la igualdad del individuo y de los grupos en que se integra sean reales y efectivas; en remover los obstáculos que impidan o dificulten su plenitud y facilitar la participación de todos los ciudadanos en la vida política, económica, cultural y social.

Asimismo, el artículo 35 de nuestra Carta Magna reza: «1. Todos los españoles tienen el deber de trabajar y el derecho al trabajo, a la libre elección de profesión u oficio, a la promoción a través del trabajo y a una remuneración suficiente para satisfacer sus necesidades y las de su familia, sin que en ningún caso pueda hacerse discriminación por razón de sexo. 2. La ley regulará un estatuto de los trabajadores».

Han pasado 40 años de aquella victoria en pro de la libertad y de la igualdad, y la pregunta que nos seguimos planteando es si realmente dicha proclama del artículo 14 se presenta en la actualidad con entidad real desde una perspectiva de género o si,

1 Juana María Gil Ruiz. Catedrática de Filosofía del Derecho. Facultad de Derecho de la Universidad de Granada. Plaza de la Universidad n. ${ }^{\circ} 1.18001$ Granada. ESPAÑA. Email: jgil@ugr.es 
por el contrario, continúa formando parte de las entelequias o de los buenos deseos políticos de un Estado que se califica de Democrático y Social de Derecho. No en vano, hace veintitrés años desde que España ratificara la Declaración y la Plataforma de Acción de la IV Conferencia Mundial sobre la Mujer de Beijing (1995). Esta última supuso el compromiso de incorporación del principio del gender mainstreaming en la totalidad de los procesos normativos - elaboración, interpretación y aplicación de la normas- y en la totalidad de las políticas públicas. Y esta misma fecha debiera indicar, en consecuencia, un antes y un después.

No queremos con esto desmerecer los importantes esfuerzos que se han hecho a nivel jurídico de adecuación de la legislación al principio de no discriminación señalado por la Constitución de 1978 y por la normativa comunitaria, todo lo contrario, pero entendemos que ni la igualdad legal-formal entre hombres y mujeres es suficiente, requiriendo medidas de carácter compensatorio, ni la falacia del igualitarismo jurídico puede llevarnos a «deponer las armas» en la lucha por la igualdad real. No en vano, el Pacto Europeo por la Igualdad de Género (2011-2020), en el contexto de la Estrategia 2020, continúa insistiendo en tres objetivos más que recurrentes en lo que a las deficiencias de igualdad efectiva ciudadana se refiere; a saber: reducir las desigualdades en cuanto al empleo y protección social; promover un mejor equilibrio entra la vida laboral y privada de mujeres y hombres; y combatir todas las formas de violencia contra las mujeres.

Luego desde la aprobación de la Constitución de 1978 hasta ahora se han modificado leyes, se han puesto en marcha acciones positivas diferenciadoras que pretenden nivelar desigualdades, y se han propuesto medidas - con mayor o menor éxito- con el objetivo de garantizar la igualdad de oportunidades en el empleo, facilitar la conciliación de la vida laboral y familiar — no tanto la personal-, impulsar la participación de las mujeres o combatir la execrable lacra social que es la violencia de género. Sin duda alguna, la aprobación unánime por todas las fuerzas políticas de la L.O.3/2007, de 22 de marzo para la igualdad efectiva de mujeres y hombres inaugura un antes y un después en el hacer jurídico y político en torno a la igualdad ciudadana ${ }^{2}$.

No obstante, y aun cuando escuchemos que la situación de las mujeres ha cambiado sustancialmente en las últimas décadas, en España todavía persiste un importante nivel de desigualdad que pone en entredicho los valores que fundamentan el orden democrático. He aquí algunos datos, ya recogidos en Gil Ruiz (2007) que a

${ }^{2}$ Al respecto, remito a: GiL RuIZ, J.M. (2012), Las nuevas Técnicas Legislativas en España, Valencia, Tirant lo Blanch.

${ }^{3}$ El trabajo que aquí defiendo, parte de la tesis principal defendida en el capítulo IV de la investigación publicada en 2007 bajo el título Los diferentes rostros de la Violencia de Género, Madrid, Dykinson. Los datos actuales, pasados una década desde su publicación, ponen de manifiesto que aún hoy, tanto la brecha salarial, la necesidad de reequilibrar la vida laboral, familiar y personal y la necesidad de combatir todas las formas de violencia contra las mujeres, se erigen entre los grandes desafíos ciudadanos del siglo XXI y exigen su re-abordaje desde el nuevo marco jurídico y político actual. 
modo de sumario y pasados ya una década, aún constatan dicha aseveración: la participación política de las mujeres, teniendo en cuenta todos los órganos de decisión, se mantiene con índices inferiores a los recomendados por la Unión Europea. El salario medio que perciben las mujeres es inferior al salario medio que perciben los hombres. Las mujeres soportan frecuentemente la acumulación de su jornada laboral al trabajo doméstico no remunerado, y éste es mayoritariamente la única actividad que desempeñan. En el caso de las familias monoparentales, éstas tienen generalmente como cabeza de familia a las madres, que a su vez representan el porcentaje más alto de parados en esta situación. Las mujeres son las principales beneficiarias de pensiones asistenciales o de viudedad que son las económicamente más bajas.

La necesidad de eliminar las diferencias existentes entre mujeres y hombres requiere la adopción de medidas urgentes que, partiendo de los desequilibrios que caracterizan las actuales relaciones de género, se encaminen a la superación de la discriminación por razón de sexo tanto desde una perspectiva individual como colectiva, con la finalidad de garantizar el derecho fundamental a la igualdad entre mujeres y hombres ${ }^{4}$.

$\mathrm{Y}$ es que «(e)l instrumental jurídico de hoy, neutro respecto al género se encuentra con una realidad sexuada —o viceversa, la realidad sexuada se encuentra con el Derecho moderno monosexuado_- Es el complicado intercambio entre vida y Derecho que se obtiene como resultado de lo que las estudiosas del Derecho de las mujeres pretenden determinar y comprender, con el objetivo específico de contribuir a una igualdad verdadera, al reconocimiento del igual valor, y la mayor libertad de las mujeres ${ }^{5}$.

Ello obliga a revisar la Constitución e incorporar la perspectiva de género de manera principal y transversal, desde el Preámbulo (donde se blindaría) hasta su parte dispositiva. Esta incorporación del gender mainstreaming no sólo afecta a la necesidad de revisar el lenguaje sexista (y excluyente) de la Carta Magna, sino a incorporar las reivindicaciones, intereses, y voces de las mujeres como ciudadanas (y trabajadoras), y no como un mero anexo, donde se extrapolen lo previsto para el ciudadano (trabajador) como plantilla de lo humano. Toda esta visión —ahora sí abierta a toda la ciudadanía - afectaría a todos los ámbitos —incluyendo el laboral- y obliga a extraerla del saco genérico del artículo 14, introduciéndola como objetivo principal main del Estado Social y Democrático del Derecho.

${ }^{4}$ Véase la Estrategia 2020. Una estrategia para un crecimiento sostenible e integrador. Comunicación de la Comisión de Bruselas, 3.3.2010, COM (2010) 2020 final.

5 Vid. STANG DaHL, T. (1986), «Building Women's Law», International Journal of the Sociology of Law, 14/3-4, p. 239. 


\section{LA PROTECCIÓN EUROPEA Y NACIONAL POR RAZÓN DE GÉNERO: UNA MIRADA AL DERECHO AL TRABAJO}

Una mirada al «deber hacer» jurídico-político europeo nos remonta —paradójicamente-a 1992, cuando la Recomendación del Consejo de la CEE, 92/442/CEE de 27 de julio de 1992 de convergencia de los objetivos y políticas de protección social $^{6}$, recomienda a los Estados miembros «contribuir a suprimir los obstáculos al ejercicio de una actividad profesional por parte de los padres con medidas que permitan conciliar las responsabilidades familiares y la vida profesional». La necesidad de conciliar la vida familiar y laboral debe percibirse como una condición vinculada de forma inequívoca a la realidad social. De hecho, ya a nivel internacional, la IV Conferencia Mundial sobre las mujeres celebrada en Pekín, en septiembre de 1995, tras recordarnos que los derechos de las mujeres son derechos humanos, lo consideró objetivo estratégico y fue ratificado, con un compromiso formal, por los 189 Estados allí reunidos. Textualmente: «La igualdad de derechos, de oportunidades y de acceso a los recursos, el reparto igualitario de las responsabilidades respecto de la familia y una relación armoniosa entre mujeres y hombres son indispensables, tanto para su bienestar y el de sus familias, como para la consolidación de la democracia» ${ }^{7}$. Y toda esta proclama la inserta en un marco de incorporación del principio del gender mainstreaming, como principio vinculante al que deben dirigirse todas las medidas legislativas, y de acción política — que incluye programas y proyectos públicos-. Este principio también fue incorporado por la Unión Europea en su acerbo comunitario que reatraviesa desde el Tratado de Ámsterdam (art. 3.2), hasta el Tratado de Lisboa (art.8), sin olvidarnos de Directivas de significativo interés ${ }^{8}$ al respecto, que obligaban a los Estados parte a transponer lo suscrito en tanto que objetivo prioritario de la Unión Europea. No en vano, se trata «de un principio firme y creciente, en el seno de la Unión Europea. En efecto, ha sido reconocido por el art. 3 del Tratado de Ámsterdam, (también en el art. 8 del Tratado de Lisboa), que ha incluido, como una de las prioridades a tener en cuenta en el diseño de Políticas Europeas, la promoción de la Igualdad de mujeres y hombres en todas las políticas y la eliminación de las discriminaciones. Se incluye como objetivo de la Unión, la promoción de la igualdad entre hombres y mujeres (hasta el punto de condicionar) el conjunto de las Políticas Comunitarias al objetivo de la consecución de esa igualdad» (Rey Martínez, 2004). Ello implica que el fin de la igualdad ciudadana no se alcanza a través de una o varias acciones específicas, sino integrándolo en todas las acciones y confirma el mayor ran-

${ }^{6}$ Recomendación del Consejo 92/442/CEE, de 27 de julio de 1992, relativa a la convergencia de los objetivos y de las políticas de protección social, en D.O.C.E., n. ${ }^{\circ}$ L 245/49, 26 de agosto de 1992.

7 IV Conferencia Mundial sobre las mujeres, Beijing, China, 4 a 15 de septiembre 1995, punto 15.

8 La Directiva 2006/54, en su artículo 29 afirma: «Transversalidad de la perspectiva de género: Los Estados miembros tendrán en cuenta de manera activa el objetivo de la igualdad entre hombres y mujeres al elaborar y aplicar disposiciones legales, reglamentarias y administrativas, así como políticas y actividades, en los ámbitos contemplados en la presente Directiva». 
go de protección europeo por razón de género frente a otros cortes sistémicos. De este modo, y como puede constatarse en la redacción del artículo 157 del Tratado de Funcionamiento de la Unión Europea, «Cada Estado miembro garantizará...» — lo que implica intervención directa e incondicionada supra-estatal - cuando se trate de discriminaciones producidas por razón de género, frente al resto de causas de discriminación que también interseccionan y reatraviesan al género, pero que no configuran un derecho de eficacia directa por ahora ${ }^{9}$. Frente a estas segundas — art. 19 TFUE«(... El Consejo (...) podrá adoptar acciones adecuadas)». Asimismo, el ámbito material de protección dispensada se configura distinto para las primeras, más rico y abierto — tocante al ámbito laboral y al no laboral—, frente al resto de causas de discriminación prohibidas que poseen una protección limitada centrada en la esfera laboral ${ }^{10}$.

En este sentido, «la Comisión de la Unión Europea ante la constatación de que decisiones políticas que, en principio, parecen no sexistas, pueden tener un diferente impacto en las mujeres y en los hombres, a pesar de que dicha consecuencia ni estuviera prevista ni se deseara, aprobó (en 1996) una Comunicación sobre la transversalidad mainstreaming —introduciéndola en el Tratado de Ámsterdam (1997)— como un primer paso hacia la realización del compromiso de la Unión Europea de integrar la perspectiva de género en el conjunto de las políticas comunitarias y elaboró una Guia para la Evaluación del Impacto en Función del Género (1998) diseñada para proyectarse en el seno de la Comisión con objeto de evitar consecuencias negativas no intencionales que favorezcan situaciones de discriminación y para mejorar la calidad y la eficacia de las políticas comunitarias» ${ }^{11}$.

De este modo, y como complemento a los objetivos de la acción comunitaria prevista para la promoción de la igualdad efectiva de mujeres y hombres, merece destacarse la aprobación de la Decisión del Consejo 2001/51/CEE, de 20 de diciembre de 2000, por la que se establece un programa de acción comunitaria (V Programa Marco) sobre la estrategia (COM 2000, 335 final) que debe seguirse en materia de igualdad de mujeres y hombres (2001-2005), sustentándose en los principios derivados de la transversalidad y en la Hoja de ruta para la igualdad entre hombres y mujeres 2006-2010. Este Programa Marco, de enfoque dual, «es uno de los instrumentos necesarios para la puesta en práctica de la estrategia global comunitaria en materia de igualdad entre mujeres y hombres, que abarca todas las políticas y todas las accio-

9 Se puede detectar también un cierto mayor grado de protección en la discriminación por razón de etnia, con un ámbito material más abierto que incluye esfera laboral y extra-laboral. Véase la Directiva 2000/43 del Consejo, de 29 de junio de 2000, relativa a la aplicación del principio de igualdad de trato de las personas independientemente de su origen racial o étnico, DOUE, n. ${ }^{\circ} 180$ de 19 de junio de 2000.

${ }_{10}$ Directiva 2000/78 del Consejo, de 27 de noviembre de 2000, relativa al establecimiento de un marco general para la igualdad de trato en el empleo y la ocupación, publicada en DOUEL, n. ${ }^{\circ} 303$, de 2 de diciembre de 2000 .

11 Exposición de Motivos de la Ley 30/2003, de 13 de octubre, sobre medidas para incorporar la valoración del impacto de género en las disposiciones normativas que elabore el Gobierno. 
nes comunitarias encaminadas a alcanzar dicha igualdad, incluidas las políticas de integración de la igualdad de los sexos y las acciones específicas dirigidas a las mujeres», y destaca por conceder un especial protagonismo a la evaluación del impacto de género en todos los ámbitos de intervención (vida económica, social, política, vida civil, roles y estereotipos,...) que tengan repercusiones directas o indirectas en las mujeres o en los hombres, «como una de las acciones a emprender para el logro de los objetivos mencionados en el referido programa» (Decisión del Consejo 2001/51/CEE, de 20 de diciembre de 2000). Ello explica el sentido de la transversalidad y exige que «en el diseño y aplicación de todas las políticas hay(a) que tener en cuenta las preocupaciones, las necesidades y aspiraciones de las mujeres, en la misma medida que las de los hombres» ${ }^{12}$.

En esta misma línea ha continuado in crescendo la Comunicación de la Comisión al Parlamento Europeo, al Consejo, al Comité Económico y Social Europeo y al Comité de las Regiones de 21 de septiembre de 2010, Estrategia para la igualdad entre mujeres y hombres 2010-2015 [COM (2010) 491 final]_-; el Compromiso estratégico para la igualdad de mujeres y hombres 2016-2019 de la Comisión Europea; la Estrategia «Europa 2020» [COM (2010) 2020 final] y como no, el Pacto Europeo por la Igualdad de Género 2011-2020.

Y no puede ser de otra forma siendo coherentes con el Tratado de la Unión (Lisboa, 2009) y con la Carta de los derechos fundamentales de la Unión Europea — que hace suya en su artículo 6.1 - que establece (artículo 23 de la Carta) que la «igualdad entre mujeres y hombres deberá garantizarse en todos los ámbitos, inclusive en materia de empleo, trabajo y retribución» y que «el principio de igualdad no impide el mantenimiento o la adopción de medidas que supongan ventajas concretas a favor del sexo menos representado».

No obstante, algunas voces ya lamentaron ${ }^{13}$ la oportunidad perdida de refundar el concepto de ciudadanía europea tanto por el Tratado de Maastricht de 1992 como por las modificaciones introducidas en Ámsterdam, insistiendo en la importancia de elaborar un concepto europeo de ciudadanía basado en la igualdad de género. Junto a Barrère, otras autoras como Freixes Sanjuán ${ }^{14}$ destacan las debilidades y «bipolaridades» de la perspectiva de género en el Tratado constitucional. En este sentido, si dentro de los objetivos de la Unión, en su punto 3 se indica que la Unión fomentará la igualdad entre mujeres y hombres, a sensu contrario quizás deba entenderse que la

12 Comunicación de la Comisión al Consejo, al Parlamento Europeo, al Comité Económico y Social y al Comité de las Regiones, relativa a una Estrategia Marco Comunitaria sobre igualdad de hombres y mujeres (2001-2005)

13 Al respecto, véase Barrère Unzueta, M.A. (2003), «Ciudadanía europea e igualdad de género», Revista Vasca de Administración Pública, n. ${ }^{\circ}$ 66, pp. 47-66.

${ }_{14} \mathrm{Al}$ respecto, consúltese especialmente de esta autora: FreiXes Sanjuán, T. (2004), «La Igualdad y el futuro de Europa», en Balaguer Callejón, M.L. (Ed.), XXV Aniversario de la Constitución Española: propuestas de reformas, Málaga, Diputación de Málaga, pp. 241-269; y la publicada en 2005, «La perspectiva de género en la elaboración de la constitución europea», en FrEIXES SANJUÁN, T. y Sevilla Merino, J. (Coords.), Género, Constitución y Estatutos de Autonomía, Madrid, INAP, pp. 69-99. 
ciudadanía no es inicialmente igual entre sí, salvo que se acepten gradaciones de igualdad.

Siguiendo con nuestra exposición, en el ámbito comunitario, la maternidad y la paternidad han sido contempladas en dos Directivas del Consejo de significativo interés. Nos referimos a la Directiva 92/85/CEE, de 19 de octubre de 1992 que contempla la maternidad desde la perspectiva de la salud y la seguridad en el trabajo de la trabajadora embarazada, que haya dado a luz o que se halle en el período de lactancia ${ }^{15}$; y la Directiva del Consejo 96/34/CEE de 3 de junio de 1996, fruto de un acuerdo entre la UNICE, el Centro Europeo de la Empresa Pública y la Confederación Europea de Sindicatos, derogada por la Directiva 2010/18/UE del Consejo de 8 de marzo de 2010, que preveía el permiso parental como derecho individual e intransferible y la ausencia del trabajo por motivos de fuerza mayor. Se trataba originariamente, según calificó la Eurocámara de «un punto de partida fundamental» en la consecución de la igualdad de oportunidades y de trato entre hombres y mujeres, aun cuando se lamentaba de que su adopción hubiera sido a través de una directiva, y no como reglamento con aplicación inmediata. La actual Directiva 2010/18/UE aplica el acuerdo marco revisado, el 18 de junio de 2009, por las organizaciones europeas de interlocutores sociales intersectoriales, matizando e innovando algunos de sus términos. Entre ellos, repárese en la Cláusula 6 de la misma titulada «Reincorporación al trabajo», que introduce —aunque a título indicativo - ciertas prerrogativas del trabajador para adaptar su jornada de trabajo tras el disfrute de un permiso parental.

En esta línea de amplitud del ámbito material de protección antes señalado tampoco pueden desconocerse — centrada en el ámbito laboral - la Directiva (de refundición) 2006/54/CE del Parlamento Europeo y del Consejo ${ }^{16}$, de 5 de julio de 2006, relativa a la aplicación del principio de igualdad de oportunidades e igualdad de trato entre hombres y mujeres en asuntos de empleo y ocupación; como la Directiva 2004/113/CE sobre aplicación de la igualdad de trato entre hombres y mujeres en el acceso a bienes y servicios y su suministro, referida al ámbito extralaboral.

Asimismo, no debemos olvidar que esta necesidad de conciliar vida personal, familiar y laboral se encuentra enmarcada también dentro del Convenio 156 de 1981 (OIT) sobre personas trabajadoras con responsabilidades familiares, así como la Recomendación 165 (OIT); o en el enfoque socio-laboral del Convenio 183 de la OIT sobre

${ }^{15}$ En la actualidad esta regulación, superada por la OIT, pretende ser modificada por otra posterior pero aún no ha logrado ser aprobada.

${ }^{16}$ Esta Directiva refunde - y sustituye desde el 15 de agosto de 2009-, a las Directivas 2002/73/ CE del Parlamento Europeo y del Consejo, de 23 de septiembre de 2002, que modifica la Directiva 76/207/CEE del Consejo relativa a la aplicación del principio de igualdad de trato entre hombres y mujeres en lo que se refiere al acceso al empleo; la Directiva 75/117/CEE relativa a la igual retribución, la 86/378/CEE sobre la igualdad de trato en regímenes profesionales de Seguridad Social (también modificada por la Directiva 96/97/CEE), y la 97/80/CEE, relativa a la carga de la prueba en los casos de discriminación por razón de sexo. 
protección de la maternidad ${ }^{17}$ y de la Carta Social Europea incidiendo en la protección «especial» de las trabajadoras.

Dentro del marco jurídico nacional, la necesidad de conciliar vida — personal— familiar y laboral tiene como fundamento los artículos 9.2, 14 y 39 de la Constitución Española, que contemplan, respectivamente, la promoción de las condiciones para que la libertad e igualdad de las personas sean reales y efectivas, el principio de igualdad ante la ley y no discriminación y la protección social, económica y jurídica de la familia. De este modo la Ley 39/1999, de 9 de noviembre de 1999 de conciliación de la vida familiar y laboral de las personas trabajadoras estructurada en 22 artículos modificaba el Estatuto de los Trabajadores, la Ley de Procedimiento Laboral, la Ley de Prevención de Riesgos Laborales, la Ley General de la Seguridad Social, algunas Leyes reguladoras de la Función Pública, así como el Real Decreto Ley 11/1998, de 4 de septiembre, por el que se regulan las bonificaciones de cuotas de la Seguridad Social de los contratos de interinidad que se celebren con personas desempleadas para sustituir a trabajadores durante los periodos de descanso por maternidad, adopción o acogimiento.

Sin embargo, la Ley de Conciliación no ha conseguido — probablemente porque no miraba hacia la corresponsabilidad - , sino todo lo contrario, difuminar las enormes diferencias existentes entre los géneros en el acceso, promoción profesional y condiciones de trabajo. La ley ha resultado ser, paradójicamente, una invitación jurídica a que el empresariado no contrate a mujeres en tanto que arbitra, entre otros, permisos retribuidos (art. 37.3.b E.T.), reducciones de jornada (art. 37.4.5 y 6 E.T) y períodos de excedencia (art. 46.3. E.T) ya no sólo para el cuidado y crianza de menores, sino para el cuidado de un familiar enfermo hasta un segundo grado de consanguinidad y/o afinidad. Pese a que la Ley fue especialmente cuidadosa en el uso del lenguaje y en todo momento habla de "personas trabajadoras», los datos sociológicos vienen a constatar que quien, mayoritariamente, se ocupa de la «ética del cuidado» son las mujeres ${ }^{18}$.

Probablemente ésta fue una de las razones, junto al compromiso adquirido con el gender mainstreaming, lo que impulsó la aprobación de la L.O.3/2007, de 22 de marzo, para la igualdad efectiva de mujeres y hombres, que modificaba la Ley de Conciliación — por cierto, posteriormente también retocada — nunca mejor dicho- por el Real Decreto Ley 3/2012, de 10 de febrero de Reforma Laboral. El objeto de la Ley de

17 No obstante, y pese a centrarse en el ámbito laboral, es importante destacar que el Convenio 183 de la OIT considera que la protección del embarazo es una responsabilidad compartida de gobierno y sociedad, conformado por cinco componentes: licencia de maternidad, protección del empleo, prestaciones dinerarias y médicas, protección de la salud (respecto a una trabajo perjudicial para la salud de la mujer o de la niña o niño) y lactancia. Véase también la Recomendación de la OIT 191 (adoptada el 15 de junio de 2000) que recoge la conveniencia de asegurar la totalidad de las rentas anteriores y aconseja una duración mínima de la prestación de maternidad de 18 semanas,

18 Según datos de la EPA del primer cuatrimestre de 2017, el $96 \%$ de las personas que reducen su jornada laboral para dedicarse al cuidado de menores son mujeres. 
Igualdad queda recogido en su art. 1.1: «Las mujeres y los hombres son iguales en dignidad humana, e iguales en derechos y deberes. Esta Ley tiene por objeto hacer efectivo el derecho de igualdad de trato y de oportunidades entre mujeres y hombres, en particular mediante la eliminación de la discriminación de la mujer, sea cual fuese su circunstancia o condición, en cualesquiera de los ámbitos de vida y, singularmente, en las esferas política, civil, laboral, económica, social y cultural para, en el desarrollo de los artículos 9.2 y 14 de la Constitución, alcanzar una sociedad más democrática, más justa y más solidaria» y para ello establecerá — según especifica en su apartado 2. - principios de actuación de los Poderes Públicos, regulando derechos y deberes de las personas físicas y jurídicas, tanto públicas como privadas, y preverá medidas destinadas a eliminar y corregir en los sectores público y privado, toda forma de discriminación por razón de sexo.

No obstante, la L.O.3/2007, de 22 de marzo, para la igualdad efectiva de mujeres y hombres, que nace con vocación de código de igualdad, y que enmarca — dentro del soft law - un conjunto de medidas para impulsar de manera fáctica la igualdad efectiva, no termina de conseguir los objetivos ambiciosos, necesarios y urgentes propuestos. Ello ha provocado que algunas voces apunten a la conveniencia de modificar nuevamente la ley por ineficiente; mientras que otras apuntan por perseguir la implementación de la misma y esperar a que el ordenamiento jurídico y político —incluyendo el insustituible compromiso de los Poderes del Estado - se empape del principio del gender mainstreaming y de la metodología de género incorporada al nuevo discurso normativo y político. No olvidemos que, según recoge el artículo 15 de la LOIEMH el principio de igualdad de trato y oportunidades informará con carácter transversal (vincúlese con el artículo 4 de la LOIEMH), la actuación de todos los Poderes Públicos; y las Administraciones públicas lo integrarán, de forma activa, en la adopción de sus disposiciones normativas, en la definición y presupuestación de políticas públicas en todos los ámbitos y en el desarrollo del conjunto de todas sus actividades. Y ello no sólo afecta a la fase de elaboración, sino a la de interpretación y aplicación de los actos normativos y no normativos, siendo su reconocimiento fundamental ${ }^{19}$.

Sea como fuere, el debate se encuentra en plena ebullición política y ciudadana y requiere de un compromiso social y político para evitar que esta previsible nueva apuesta legislativa — también a nivel constitucional—o desarrollo reglamentario pueda seguir abandonando a las mujeres al albur de las necesidades reproductivas sociales o a los abusos patriarcales del sistema productivo. No olvidemos, que al no ser las mujeres sujetos constitucionalmente definidos ${ }^{20}$ en nuestro actual Estado de

19 Véase Lousada Arochena, J.F., «La integración de la perspectiva de género en la aplicación e interpretación de las normas por la jurisdicción social», Revista de Derecho Social, 2016, n. ${ }^{\circ}$ 76, pp. 39-58.

${ }^{20}$ En este sentido, nos sumamos a la tesis defendida por Astola Madariaga, J. (2008), «Las mujeres y el estado constitucional: un repaso al contenido de los grandes conceptos del Derecho Constitucional», en Astola Madariaga, J. (Ed.), Mujeres y Derecho: Pasado y presente. I Congreso multidisciplinar de la Sección de Bizkaia de la Facultad de Derecho, p. 267. 
Derecho, esta situación las coloca en una posición de falta de garantía de protección de sus derechos — como ciudadanas — frente a la de los hombres, que sí la tienen como ciudadanos.

\section{LA PERSISTENCIA DE LA BRECHA DE GÉNERO Y LA URGENCIA DE UNA RESPUESTA CONSTITUCIONAL}

Si el conflicto de clases fue un elemento clave para entender la existencia del Estado Social o de Bienestar en el siglo pasado, lo cierto es que el llamado conflicto de Género lo es para la comprensión de la Crisis Global del siglo XxI y enmarca, sin duda, los nuevos desafíos de esta nueva era. Se trata de la expresión más cruda de la crisis sistémica y global en la que estamos inmersos que, a su vez, descansa en una crisis acumulada y multidimensional que afecta a la Sociedad del Trabajo y, cómo no, a la crisis de los cuidados. Sin embargo sorprende que, pese a la urgencia de recuperar este tipo de análisis con perspectiva de género, éstos apenas aparezcan en los discursos dominantes y menos aún en los académico-jurídicos ${ }^{21}$. Y el dilema se reduce a la reflexión — comprometida - de si la situación de las mujeres, en tanto que ciudadanas y más de la mitad de la población, ha cambiado sustancialmente en las últimas décadas o si, por el contrario, aún persiste un importante nivel de desigualdad que cuestiona los valores democráticos. Y la respuesta a nuestro interrogante, sin duda, gira en torno a dos cuestiones claves que requieren de un nuevo enclave constitucional, esto es de una «reforma constituyente»: las consecuencias de la división público-privado de los espacios donde se producen y reproducen las distintas relaciones humanas y el reconocimiento de la subjetividad política y jurídica de las mujeres.

Siendo conscientes, como diría Alda Facio ${ }^{22}$, que a veces, la preocupación — casi obsesiva - por justificar cada una de las aseveraciones —obvias - de la posición penalizada de las mujeres en el ámbito laboral, nos hace perdernos entre datos en demérito de la teoría, lo cierto es que los números hablan por sí solos —apenas se eche un vistazo al contexto socio-laboral - y ponen de manifiesto que las constantes denunciadas por la Teoría jurídica-política feminista insisten y persisten. No en vano en otros trabajos ${ }^{23}$ se denunciaba que las mejoras legales no han traído consigo «mejoras» para las mujeres, sino una peligrosa apariencia de igualitarismo y un reloj hipotecado que obliga a las mujeres a tener que decidir — no haciendo uso de su libre albedrío-, si dedicarse a la función doméstica, si participar en el mercado laboral o, las más atrevidas, si hacerse un hueco en el mundo de la política. Compatibilizar todo

${ }^{21} \mathrm{Al}$ respecto, véase EsQuembre CeRDÁ, M. (2016), «Las mujeres ante el cambio constitucional. Algunos apuntes desde una perspectiva feminista para una «reforma constituyente» de la Constitución Española», Atlánticas. Revista Internacional de estudios feministas, 1, (1), p. 285.

${ }_{22}$ Resulta de especial relevancia la obra de Facio Montejo, A. (1993), Cuando el Género suena, cambios trae. Una metodología para el análisis del fenómeno jurídico desde la perspectiva de Género, Ilanud.

${ }^{23}$ Vid. Gil Ruiz, J.M. (2007), Los diferentes rostros de la Violencia de Género, opus cit., p. 137. 
era y es casi una «misión imposible», frente al uso del tiempo de los varones, libre de ataduras y reconocido en las estadísticas oficiales. Si el tiempo de trabajo no remunerado se realiza mayoritariamente en el hogar y su volumen se está comenzando a estimar tímidamente ${ }^{24}$ y con bastantes limitaciones, a partir de encuestas y estudios; el tiempo de trabajo remunerado, que es el reconocido, se considera desde una amplia cobertura estadística. En este sentido, las mujeres españolas aún engrosan las listas de «población inactiva» ${ }^{25}$ ya que «no trabajan» por dedicarse a las labores del hogar travestidas bajo el título de «amor de casa» — entenderse que no producen bienes o servicios para la comunidad-, frente al número de varones activos y ocupados que duplican al de mujeres.

Asimismo, y en la misma línea de lo denunciado en el trabajo anterior, buena parte de las mujeres «productivas» se ven obligadas a desertar del ámbito público laboral, al no poder compatibilizarlo con el trabajo doméstico cada vez más cargado por las nuevas circunstancias socio-culturales (incremento de la tercera y cuarta edad por inversión de la pirámide demográfica) y carecer de medios y recursos económicos y temporales. En estas circunstancias, pensar en promoción laboral de las mujeres es, entre otras razones, prácticamente quimérico en tanto que se ven abocadas a la renuncia profesional, en mayor o menor medida, durante los años de «reproducción», y a ocuparse de la tareas pre-asignadas de atención y cuidado de los otros — menores, enfermos y ancianos en segundo grado de consanguinidad y/o afinidad-, ahora también por ley.

Las condiciones, pues, previas al desempeño de las tareas profesionales siguen siendo significativamente diferentes para hombres y mujeres. De hecho, la desigual distribución de las responsabilidades domésticas sigue constituyendo - y vuelve a reconfirmarse ${ }^{26}$ como- una de las principales barreras microsociales que la mujer encuentra para ser activa en el mundo laboral, ya que dicha desigualdad determina que la mujer tenga una menor disponibilidad de la energía física, mental y afectiva para dedicar a su empleo y profesión, además de cierto grado de «desequilibrio»

24 Para subsanar dicha laguna, merecen destacarse los esfuerzos realizados por la Economía feminista. Entre los trabajos más recientes, véase GÁlvez MuÑoz, L. (dir.) (2016), La economía de los cuidados, Sevilla, deculturas.

${ }^{25}$ Las personas que se incluyen en el ítem de Población inactiva son aquéllas que no producen bienes o servicios para la comunidad. A esta categoría pertenecen pensionistas y personas jubiladas, las y los estudiantes, las personas con incapacidad permanente y las «amas de casa». La población activa es la población ocupada más la población parada, y se define como el conjunto de personas de una edad determinada (entre los 16 y los 65) que, en un período de referencia dado, suministran mano de obra para la producción de bienes y servicios económicos o que están disponibles y hacen gestiones para incorporarse a dicha producción. Se encuentran en este grupo aquellas personas que cuentan con un empleo o están en disposición de tenerlo, es decir, la población ocupada y la parada entre los 16 y los 65 años.

26 Dicha tesis ha sido recientemente reconfirmada por KLEVEn, H. J., LANDAIS, C., SogaARD, J. E. (2017), Children and Gender Inequality: Evidence from Denmark, New York. https://www.henrikkleven. com/uploads/3/7/3/1/37310663/kleven-landais-sogaard_gender_feb2017.pdf 
mental (ya conocemos los síndromes psiquiátricos de moda, porque no pasan: «la superwoman», «la abuela esclava»...). Y el empresario, y digo bien, en masculino, lo sabe: el 30\% de los hombres empresarios ${ }^{27}$ prefiere contratar a un varón en su empresa, al tiempo que el 57,6\% piensa que existen perfiles profesionales más adecuados y propios de hombres y otros de mujeres. Quizás por esta razón, el 60\% de las mujeres que trabajan a tiempo parcial lo hacen, no por mor de la voluntas, sino porque no ha podido encontrar trabajo en jornada completa; y en segundo término, porque debe ocuparse del cuidado de personas dependientes (menores y/o personas adultas enfermas, incapacitadas, en segundo grado de consanguinidad y/o afinidad).

Y los datos, ya denunciados en $2017^{28}$, vuelven a resultar reveladores: la diferencia de trabajo realizado por las mujeres en España, pero que no es reconocido porque no es remunerado —eso que gusta llamarse «labores del hogar o amor de casa»— se calcula en 91 días al año. Y la propia inercia nos incita a seguir sumando. Si a los 91 días de trabajo extra dentro del hogar, sumamos los 88 días que se calcula —según datos de la Encuesta Anual de Estructura Salarial- éstas trabajan de más que sus compañeros varones para conseguir cobrar lo mismo (24\% de brecha salarial), el resultado es un total de 179 días gratis de trabajo al año. Ciertamente, quien puede desaprovechar las ventajas de beneficiarse del «trabajo» de las mujeres — autoestimuladas - además de ser, paradojas de la vida, el recurso humano más preparado hoy por hoy en España. Dicho esto, es de entender, pues, que éstas cobren casi un 40\% menos de pensión que los hombres; y que engrosen las listas de pensiones no contributivas (el $70 \%$ de quienes la reciben son mujeres). Es lo que tiene el seguir considerando trabajo aquel que se encuentra dentro del mercado productivo, directamente generador de bienes y servicios y empeñarse en no redefinirlo.

Pero llegado este punto, el siglo XxI debe afrontar el reto nada fácil de aparcar las palabras y ponerse a hacer para dejar de girar en torno a debates estériles sobre la igualdad efectiva ciudadana. Tal y como denunciábamos en Hablemos otra vez de igualdad pero hagamos alguna vez algo de verdad, reflexionar sobre un modelo igualitario que permita conciliar la vida personal, profesional y familiar de las personas, implica reconocer el enorme y fructífero trabajo que las mujeres realizan dentro del hogar,

${ }^{27}$ Frente al $30 \%$ de los hombres empresarios que prefieren contratar a un varón en su empresa, al $75,5 \%$ de las mujeres empresarias le es indiferente que sea hombre o mujer. El porcentaje que tiene preferencia $(24,5 \%)$ se reparte equitativamente entre la opción de trabajador o trabajadora. En cambio, los hombres empresarios que muestran neutralidad representan sólo el 69,5\% del total y el 30\% restante, como decíamos al inicio, prefiere con exclusividad a un hombre para su empresa. Datos provenientes de un estudio elaborado por el Instituto Andaluz de la Mujer, el Centro de Estudios Andaluces y la Universidad de Málaga, 2017, realizado por Óscar Marcerano. Asimismo, no debe desconocerse la aportación y datos de la obra de Castaño, C. (dir.) (2015), Las mujeres en la gran recesión: políticas de austeridad, reformas estructurales y retrocesos en la Igualdad de Oportunidades, Valencia: Cátedra, Colección Feminismos.

${ }^{28}$ Vid. Gil RuIz, J.M. (2017), «Hablemos otra vez de igualdad pero hagamos alguna vez algo de verdad», Huffingthon post, 8 de marzo de 2017. Accesible en https://www.huffingtonpost.es/juana-mariagil-ruiz/hablemos-otra-vez-de-igualdad-pero-hagamos-alguna-vez-algo-de-v_a_21875471/ 
con la consiguiente valoración en lo que a consecución de bienestar se refiere; y significa tenerlo muy presente en el momento de arbitrar medidas institucionales, con el fin de no adjudicar - y legitimar- éstas y otras tareas nuevamente sobre las espaldas de las mujeres. De no hacerlo así, el Estado contribuirá al mantenimiento del sistema patriarcal; creará ilusiones ópticas de igualdad; asignará las funciones domésticas según sexo; y contribuirá, con su aportación institucional, a la generación y mantenimiento de la violencia estructural contra las mujeres: si las mujeres no participan es porque no quieren. Y es aquí donde el Estado se erige como gran maltratador. Un Estado que siga impulsando el trabajo solapado y silencioso de las mujeres en el hogar; que no reconozca el valor social de la maternidad; que no arbitre medidas institucionales de apoyo a la conciliación, mirando fijamente a los ojos de las mujeres; que siga sin intervenir en los procesos de socialización diferencial; que quiera cubrir objetivos sociales reduciendo como sea y a costa de quien sea el gasto público; que se legitime con una legislación aparentemente tuitiva e igualitaria; que potencie el abandono del desarrollo profesional de más de la mitad de la ciudadanía... no puede tacharse, en ningún caso, de Social y Democrático de Derecho, tal y como reza el artículo 1.1 de nuestra Constitución española. Y estos adjetivos son más que meras palabras que vienen a embellecer nuestro texto legal, sino que obligan de manera imperativa, y cuyo cambio —o apenas matización — generaría la modificación de la Ley de leyes según el mecanismo arbitrado por el art. 168 de la Constitución. De no activar medidas efectivas que permitan el desarrollo fáctico de la igualdad ${ }^{29}$ y la participación de la ciudadanía en la vida social, cultural, económica y política del pueblo (art. 9.2 de la Constitución), será el Estado quien aplique violencia contra las mujeres - por omisión-, no permitiendo el desarrollo pleno y libre de su autonomía personal. Y es que cuando hablamos de mujeres, hablamos de ciudadanía y la máxima laissez faire, laissez passer — mirando hacia otro lado—-, aquí no vale.

Pues bien, en nuestra línea de (re)pensar y sugerir medidas dirigidas a la eliminación de la discriminación y a la consecución del ejercicio de los derechos humanos y las libertades fundamentales para las mujeres sobre la base de la igualdad de mujeres y hombres, se nos plantea un enorme reto en el ámbito laboral: encontrar un modelo satisfactorio para mujeres y hombres coherente con las expectativas de la vida familiar y profesional, más aún ante las profundas transformaciones que están afectando al modo en que se relacionan éstos en dichos ámbitos. Ello exige la necesidad de modificar los términos y condiciones en que tienen lugar estas relaciones, a través de una puesta en común que conduzca a la redefinición de la correspondencia de tales espacios y tiempos de trabajo.

$\mathrm{Y}$ es que «(r)epensar el Derecho y su función social es un desafío que va más allá de contar con buenas leyes o con buenas resoluciones judiciales para las mujeres.

29 Tamar Pitch se refiere a la necesidad de «tomar en serio las experiencias de las «mujeres»y partir de las mismas bien para hacerlas visibles al Derecho, bien para crear derechos a su medida», en Pitch, T (2003), Un Derecho para dos. La construcción jurídica de género, sexo y sexualidad, Madrid, Trotta, p. 259. 
Significa hacer de esta disciplina un instrumento transformador que desplace los actuales modelos sexuales, sociales, económicos y políticos hacia una convivencia humana basada en la aceptación de la otra persona como una legítima otra y en la colaboración como resultante de dicho respeto a la diversidad $»^{30}$.

Dicho reto, nada fácil, requiere recuperar — tal y como hemos advertido en anteriores publicaciones ${ }^{31}$ - en primer lugar, el panorama socio-laboral en el que las mujeres participan —apenas apuntado en nuestra intervención-, así como mostrar, en segundo lugar, la situación en la que se encuentra nuestro Estado de Bienestar para conocer de manera directa cuáles van a ser algunos de los obstáculos o peligros que deberemos salvar en nuestra reflexión jurídico-política. No podemos obviar que cuatro de los baluartes sobre los que se sustentaba el Estado Social han comenzado a tambalearse provocando importantes tensiones en los ámbitos profesional, familiar y asistencial. Nos referimos al equilibrio entre las generaciones; los matrimonios estables y la unidad familiar; el empleo continuo y a tiempo completo; y, por último, un limitado nivel de conflicto entre la vida profesional y familiar.

No hacerlo así, esto es, no tener en cuenta la inversión de la pirámide demográfica, el descenso preocupante de la natalidad y el aumento de la tercera y cuarta edad, la crisis de acumulación, la crisis fiscal y de legitimación del Estado de Bienestar y la imposibilidad de prescindir de una mano de obra barata y auto-estimulada como es la femenina, supondrá volver a perpetrar una nueva violencia contra las mujeres, esta vez de la mano del Derecho y del Estado.

\section{ALGUNAS PROPUESTAS CONCLUYENTES Y DE MEJORA JURÍDICA Y POLÍTICA}

Acorde con el Plan Estratégico de Igualdad de Oportunidades (2014-2016) y con el actual Plan Estratégico (2018-2021), destacan dos objetivos —aún caballos de batalla- de especial relevancia para fomentar la igualdad de género en materia de empleo: la lucha contra la discriminación salarial (eje I) y la conciliación de la vida personal, familiar y laboral, junto a la corresponsabilidad en la asunción de las responsabilidades familiares (eje II). Sin duda, la necesidad de resaltar y promover el trabajo (en sentido amplio) de las mujeres, sus aptitudes y destrezas, se erige como pieza clave para combatir la brecha de género que, sin duda, también afectará a la clasificación, valoración y promoción profesional.

En tanto que la resolución de dichos problemas, sin duda, van de la mano, se hace necesario que las relaciones entre el mundo laboral, la esfera doméstica, el Estado y las necesidades sociales, sean transformadas. Y ello es así porque de su superación

${ }^{30}$ Vid. Facio Montejo, A y Fries, L. (1999), Género y Derecho, Santiago de Chile: LOM Ediciones, p. 22.

${ }^{31} \mathrm{Al}$ respecto, GiL Ruiz, J.M., Los diferentes rostros de la Violencia de Género, opus cit., pp. 135 y ss. 
depende tanto la reproducción social, como el logro de la igualdad material ciudadana. Se exige la corresponsabilidad individual y colectiva, pero también se requiere que las organizaciones, agentes y también instituciones se impliquen en reformular los tiempos y experiencias de la vida de mujeres y hombres, al unísono con lo dispuesto en la Estrategia Europa 2020, en el Compromiso estratégico para la Igualdad entre mujeres y hombres 2016-2019 y en las Directrices integradas para las políticas económicas de los Estados miembros ${ }^{32}$.

Aún apelando a un principio pragmático de utilidad, el Secretario General de la OCDE se manifestaba de este modo en 2013: «La población mundial está envejeciendo y este reto puede ser abordado si todo el talento disponible se moviliza. Los gobiernos deben avanzar en el acceso y la calidad de la educación para todos, mejorar los sistemas fiscales y de prestaciones, y hacer que el cuidado de los niños sea más asequible, con el fin de ayudar a que las mujeres contribuyan al crecimiento económico y a una sociedad más justa» ${ }^{33}$.

Todas estas constantes hemos de tenerlas muy presentes en un contexto de crisis del Estado de Bienestar como el que estamos padeciendo y que se manifiesta con características claras y alarmantes a corto-medio plazo: Inversión de la pirámide demográfica (descenso drástico de la natalidad e incremento de la 3. ${ }^{a}$ y 4 . $^{\mathrm{a}}$ edad a la que habrá que cuidar); necesidad urgente de reducir gasto público; imposibilidad de prescindir de una mano de obra barata y autoestimulada como es la femenina; e impacto de la $4 .^{a}$ Revolución Industrial centrada en la robotización y donde las mujeres se encuentran muy mal posicionadas. He aquí algunas de nuestras propuestas de cambio, - no exclusivas sino aproximativas, ni necesariamente ordenadas jerárquicamente-, centradas, en buena medida, en recuperar el derecho de conciliación vinculado al derecho y deber de trabajar, como lo que debe ser: un ámbito que requiere de especial protección y promoción ${ }^{34}$ y que no es susceptible de recortes ni postergaciones.

1. Conformación de un nuevo marco constitucional y de una normativa laboral, tanto legal como convencional, que incorpore una perspectiva de género de manera principal y transversal (que supere la tradicional visión masculina y patriarcal). Ello permitirá transcender la configuración de las mujeres como

32 Debe destacarse la Directriz 7. a de las Directrices integradas en la Recomendación del Consejo de 27.4.2010 SEC (2010) 488 final que establece: «(...) Las medidas de conciliación de la vida personal y la vida laboral deberán conjugarse con la oferta de servicios asequibles y con innovaciones en la organización del trabajo a fin de aumentar los índices de empleo, especialmente entre los jóvenes, los trabajadores de mayor edad y las mujeres, procurando que las mujeres altamente cualificadas en los ámbitos técnicos y científico no abandones sus empleos».

33 Palabras del Secretario General de la OCDE, Ángel Gurría, durante la presentación del informe «Closing the Gender Gap: Act Now», en el Foro sobre Género en París en enero de 2013.

34 Este enfoque es el exigido tanto en L.O.3/2007, de 22 de marzo para la Igualdad efectiva de Mujeres y Hombres, en la jurisprudencia reciente del TC (STC 26/2011), así como en la normativa comunitaria ya referida. 
anejos en el ámbito laboral — trabajador atípico- que parece prestar sus servicios a tiempo parcial o con temporalidad. De esta forma se dará entrada a todo aquello que tiene que ver con las reivindicaciones, intereses, y demandas de las mujeres, propias a su sexo y humanidad, como ciudadanas, como en su momento se acogieron las reivindicaciones, intereses y demandas de los hombres, en tanto que ciudadanos, propias de su sexo y humanidad.

2. Necesidad de revisar el sistema de Seguridad Social, gestado en un marco de relaciones de trabajo desfasado, pensado en el varón como sustentador de la economía familiar frente a la mujer, esposa — centrada en las tareas de cuidado- $\mathrm{y}$ dependiente de sus derechos sociales. Actualmente, el déficit de integración de las mujeres en el mercado laboral — siendo el recurso humano más preparado-, genera un déficit de eficacia, pero también un déficit de equidad. Las desigualdades inter-géneros se perpetúan, pero también se retroalimentan, ampliándolas y empujan a las mujeres a la precariedad durante su vida laboral y a la dependencia económica. En este sentido, el Estado Social debe construirse sobre la lógica de la sostenibilidad de la vida ${ }^{35}$ (con sus tiempos) y no sobre las del mercado, propia de la división tradicional doméstico/público.

3. Necesidad de valorar y reconocer las destrezas y aptitudes de las mujeres, así como su responsabilidad, esfuerzo y condiciones de trabajo ${ }^{36}$, para subvertir la escala de valoración de factores en los procedimientos cuantitativos (y cualitativos) como técnica de recursos humanos. La constante de sobreponderación de los méritos patriarcales (centrados en cuestiones «económicas»), frente a la subestimación de los méritos tradicionalmente considerados femeninos (precisión, destreza, coordinación manual), sigue colocando a las mujeres en subsectores productivos — poco reconocidos ni valorados- continuadores de las tradicionales funciones asignadas en el ámbito doméstico.

4. Actuar en educación y concienciación social que debe insistir en la necesidad de apostar por otro modelo de mujer, no lastrado ni hipotecado, dependiente de la dependencia de los demás (esposo+prole+progenitores). Se trata de trabajar hacia un nuevo modelo de subjetividad, libre y no lastrado que permita saltar al ámbito de la ciudadanía con mayúsculas, sin muletas ni andadores.

5. Asimismo debe enseñarse la importancia del cuidado (propio y ajeno), y reconocer, en tanto que responsabilidad social (art. 14.7 de la LOIEMH) y colectiva (que no problema individual de las mujeres), la ineludible tarea de

35 En este sentido, remito al epígrafe «Propuestas para un uso más humano de la vida», incluido en: Gil Ruiz, J.M. (2007), Los diferentes rostros de la Violencia de Género, opus cit., pp. 149 y ss.

${ }^{36} \mathrm{Al}$ respecto, véase la Directiva 2006/53/CE y el trabajo de los servicios de la Comisión que acompaña al informe sobre su aplicación, así como la Guía «Promoción de la Igualdad salarial por medio de la evaluación no sexista de los empleos», publicada por la OIT en 2008. 
conciliación de la vida familiar, laboral y personal, enfocada hacia la corresponsabilidad. Se trata de una cuestión estructural que reclama cambios $^{37}$, aún hoy, no resueltos y que reatraviesa la economía, la política, la cultura, la ética, y por supuesto, el Derecho.

6. Reconocimiento y garantía de presencia de mujeres ${ }^{38}$ en tanto que ciudadanas en todos los ámbitos de la vida: cultural, económica, social, política. Ser ciudadana va vinculado a la participación efectiva y a la posibilidad de dar (y tener) palabra «reconocida» (y no devaluada) en el foro. En este sentido, ya no basta, por ejemplo, con que los Poderes Públicos «procurarán atender al principio de presencia equilibrada de mujeres y hombres en los nombramientos y designaciones de los cargos de responsabilidad que les corresponde» (artículo 16 LOIEMH)», acogiéndose a medidas de cambio indirectas promovidas a través de soft law, sino cambios directos y de efectos inmediatos. Si no se está, no se puede participar, aparte de ser una demanda vinculada con el mandato recogido en el art. 1.2 de la Constitución: «La soberanía nacional descansa en el pueblo español (compuesto por ciudadanas y ciudadanos) del que emanan los poderes del Estado».

7. Reconocimiento y promoción de la maternidad, en tanto que generadora de bienes sociales y evitar cualquier hermanamiento - formal o informal — con la enfermedad. En este sentido, deben repensarse los permisos de maternidad y paternidad (art. 44 de la LOIEMH) — que han de ser ante todo y sobre todo, intransferibles_- ${ }^{39}$. Recientemente el permiso de paternidad acaba de ser reformado en la legislación española con el ánimo de equiparar progresivamente los permisos de paternidad y de maternidad para hacerlos igualitarios en tres años. El 1 de marzo de 2019, el Consejo de Ministros aprobó la ampliación del permiso de paternidad de 5 a 8 semanas. El cambio entró en vigor el 1 de abril, pese a su publicación en el BOE del 7 de marzo, justificado en la conveniencia de que las empresas tuvieran tiempo suficiente para adaptarse. De este modo, en 2019 el permiso de paternidad ascenderá a 8 semanas, en 2020 alcanzará las 12 semanas y finalmente, en 2021 las 16 semanas. Asimismo debe garantizarse de manera absoluta el retorno al empleo tras el disfrute de cualquier permiso parental y apostar por una política

37 Al respecto, véase la aportación de MARrades, A. (2016), «Los nuevos derechos sociales: el derecho al cuidado como fundamento del Pacto Social», en UNED. Revista de Derecho Político, n. ${ }^{\circ} 97$, pp. 209-242.

38 Al respecto, véase Salazar Benítez, O. (2015), «Ciudadanía, género y poder: la paridad como principio constitucional», en Cuestiones de género: de la igualdad y la diferencia, n. ${ }^{\circ}$ 10, pp.16-37.

39 El pasado 25 de junio de 2018 se presentaba en el Congreso la propuesta de Ley de permisos parentales iguales e intransferibles para nacimiento, adopciones y acogimientos, que pretende elevar a 16 semanas el permiso de ambos progenitores. La iniciativa originaria es la defendida desde 2011 por la Plataforma Permisos Iguales e Intransferibles de Nacimiento y Adopción (Ppiina). No obstante, no debe perderse de vista la importancia de proteger la salud de la madre. Finalmente el Consejo de Ministros, con fecha de 1 de marzo de 2019, ha dado luz verde a la ampliación del permiso de paternidad. 
de incentivos al empresariado (ahora eliminados ${ }^{40}$ ) para compensar cualquier desequilibrio al respecto. En esta línea, el proyecto de Ley de Presupuestos Generales del Estado de 2017 añadía la disposición adicional obligatoria que confirma la necesidad de incluir una bonificación (50\% en sus aportaciones a la Seguridad Social) para aquellas empresas que destinen a sus trabajadoras embarazadas - con riesgo en el embarazo o durante la lactancia naturala otro puesto de trabajo o función específica compatible con su estado. Es sabido - y lo confirma la propia OCDE en su informe de $2013^{41}$ - que la falta de apoyo a la maternidad perjudica las perspectivas profesionales de las mujeres, pese a sus avances en la educación y el empleo.

8. Revisión del concepto de flexibilidad del tiempo de trabajo —actualmente unidireccional, en el sentido de adaptación a las necesidades productivas de las empresas- en atención a las necesidades vitales de las personas. Esta prioridad a las necesidades de las empresas, reforzada tras la última reforma laboral por Real Decreto Ley 16/2013, de 20 de diciembre, de medidas para favorecer la contratación estable y mejorar la empleabilidad de las personas trabajadoras, no sólo afecta a la «penalizada» reducción de jornada por cuidado de personas enfermas, sino también al impulso de los contratos a tiempo parcial, en detrimento de las mujeres, en tanto que sujeto directamente afectado. Se requiere su urgente revisión y el consecuente impulso a la conciliación de la vida personal, familiar y laboral, (aún más) lastrado tras la posibilidad de horas complementarias «de aceptación voluntaria», así como el establecimiento de la reducción de la jornada con márgenes más abiertos y flexibles, tanto en la reducción mínima como en la máxima, mirando —esta vez- a los ojos de la ciudadanía.

9. Apuesta por una red de servicios sociales solventes para restringir las prácticas más informales de cuidado de las personas (problema a corto-medio plazo con la inversión de la pirámide demográfica y aumento de la tercera y cuarta edad). Esta red no debe centrarse sólo en el ámbito rural —artículo 30.4 LOIEMH - sin duda, necesitado del mismo, sino que debe trasladarse también al urbano, donde las mujeres están pagando un alto precio ${ }^{42}$ por las responsabilidades adjudicadas por sexo.

${ }^{40}$ La disposición derogatoria única, apartado 1, letra f), de la Ley 3/2012, de 6 de julio, deroga el artículo 4.2 de la Ley 43/2006, de 29 de diciembre, para la mejora del crecimiento y del empleo, que regulaba las bonificaciones en las cotizaciones por reingreso tras la maternidad o excedencia por causa de conciliación.

${ }^{41}$ Informe de la OCDE «Closing the Gender Gap: Act Now», enero de 2013.

42 Según el informe de 2013 de la OCDE «Closing the Gender Gap: Act Now», revela que las mujeres están pagando un elevado precio por su maternidad y por el particular papel social que le ha tocado jugar en el ámbito familiar, con elevados gastos en guardería, problemas en el acceso a dichas instalaciones y altos impuestos que le exigen trabajar más. Asimismo se muestra que la diferencia salarial media entre hombres y mujeres se amplía al $22 \%$ en las familias con uno o más hijo/as. En general, la penalización salarial por tener hijo/as es en promedio un $14 \%$. Asimismo, el impacto de desigualdad 
10. Impulso de prestaciones ${ }^{43}$ y subsidios familiares solventes que constituyan un entramado potente de prestaciones de Seguridad Social; a saber: subsidio parental de educación, subsidio por hijo/as de corta edad, ayuda al empleo de cuidado de niño/as (tanto por lo que se refiere al salario como a las cotizaciones sociales), subsidio para el cuidado de niño/as a domicilio (especialmente recomendable para progenitores con horarios penalizados) y potenciación del sistema de guarderías (gratuitas y de calidad). Estas medidas han supuesto que en Francia, el 85,4\% de las madres con un vástago de menos de seis años esté trabajando. Asimismo, se deberían arbitrar subsidios pensados para paliar la urgencia y requerimiento de cuidados para la tercera y cuarta edad.

11. Flexibilizar el trabajo remunerado (supresión de la ausencia de horarios, especialmente para las personas trabajadoras de grupos superiores). Se pretende desviar el criterio de valoración de los cuadros desde la tradicional disponibilidad hacia su eficacia.

12. Mejorar y potenciar la promoción laboral de las mujeres tanto en el ámbito privado como público o semi-público. Algunos datos reclaman dicha medida. Con respecto al primero —el ámbito privado_ de 2015 a 2016, el porcentaje de mujeres directivas en los Consejos de Administración del Ibex subió apenas del $13 \%$ al $20 \%$. En $2017^{44}$ el incremento ha sido de un esquelético 1,1\% lo que corrobora una evidente ralentización con respecto al año anterior. En relación al segundo — el ámbito público o semi-público — la RAE es un buen ejemplo de cómo urgen medidas de acción positiva diferenciadora. De casi un total de 500 miembros que han ostentado un lugar en la Academia a lo largo de su historia, sólo 11 han sido mujeres y ninguna ha sido directora. En la actualidad sólo hay 8 de 44 miembros, lo que apenas alcanza un $18 \%$ de presencia de mujeres como ciudadanas en el espacio de la palabra ${ }^{45}$. Este anacro-

salarial es dramática para las mujeres pues al tener menor presencia en el empleo formal —el que cotizafrente al mayor nivel de especialización e impacto en el trabajo no remunerado en el hogar, generará que buena parte de ellas se jubilen con pensiones muy bajas.

${ }^{43}$ Durante la presentación del proyecto de los Presupuestos Generales de 2017, el Gobierno ha confirmado la previsión de un incremento del 11\% del gasto de 2017 para el conjunto de prestaciones que aparecen vinculadas a la cesación temporal en el trabajo por nacimiento de hijo, maternidad, paternidad, riesgo durante el embarazo y riesgo durante la lactancia con una dotación de 2.450 millones de euros.

${ }_{44}$ Informe IESE Business School y Atrevia, sobre la presencia de las mujeres en la dirección de las grandes empresas españolas, 2017.

45 Probablemente la activación de este tipo de medidas de acción positiva diferenciadora que permitiera el acceso de las mujeres — en tanto que mitad de la población — a ámbitos patriarcales muy marcados como es la RAE lograría el avance de medidas jurídicas — por otra parte, impulsadas desde la Unión Europea- como es el uso inclusivo y no sexista del lenguaje en el ámbito administrativo, pero también en la totalidad de las relaciones sociales, culturales y artísticas (art. 14.11 LOIEMH). Asimismo, podrían minimizarse las reticencias existentes por parte de algunos académicos para colaborar con el mandato jurídico de representación ciudadana. Sirvan las palabras de Arturo Pérez Reverte, académico de la RAE, al respecto, recogidas en su artículo «No siempre limpia y da esplendor», y publicadas en su sección Patentes de Corso en XL Semanal, de 3 de octubre 
nismo permanente y enquistado probablemente justifique la activación de medidas de acción positiva diferenciadora previstas (art. 11 de la LOIEMH) para motivar cambios en cumplimiento de objetivos previos marcados, en sectores reticentes ${ }^{46}$.

13. Impulsar el emprendimiento femenino (En el 2012 se calculaba que un $4 \%$ de las mujeres locales había iniciado una actividad por cuenta propia. Tres años más tarde esa cifra aumentó únicamente hasta el 5,4\%).

14. Persecución de la obligación general (art. 14 de la Constitución y art. 17.1 ET) y del mandato específico a las empresas, previsto en nuestra legislación laboral (art. 85.1 ET, art. 45 y 46 de la LOIEMH), de actuar para evitar situaciones de discriminación y negociar medidas para promover la igualdad de trato y de oportunidades entre mujeres y hombres en el ámbito laboral. Cierto es que ateniéndonos a la literalidad de la ley (art. 85.1 ET), ésta repara en el «deber de negociar» pero no en la «obligación de llegar a acuerdos». En la necesidad de fiscalizar que los mandatos jurídicos se cumplan, urge el empoderamiento de los Servicios de Inspección Laboral. La urgencia de evaluar (para evitar su devaluación) la elaboración, ejecución y seguimiento de los Planes de Igualdad de la Empresas obligadas a incorporarlos en su acervo normativo, así como activar una política eficaz de sanciones, en caso de incumplimiento, permitiría acortar la brecha de género (salarial, de promoción y condiciones de trabajo) de cada una de éstas.

15. Relanzar el distintivo de excelencia «Igualdad en la empresa» para premiar las buenas prácticas y los cambios a través del carácter persuasivo (que no solo sancionador) de las medidas jurídicas y políticas arbitradas. Ello facultaría para fomentar en la pequeña y mediana empresa (99.84\% de nuestro

de 2016: «Y es que, como dije antes, en la RAE hay de todo. Gente noble y valiente y gente que no lo es. Académicos hombres y mujeres de altísimo nivel, y también, como en todas partes, algún tonto del ciruelo y alguna talibancita tonta de la pepitilla. En Felipe IV sigue cumpliéndose aquel viejo dicho; hay académicos que dan lustre a la RAE, y otros a los que la RAE da lustre. Que acabaron ahí por carambolas, cuotas o azares, y deben a la Academia buena parte de lo que son, o aparentan ser, ahora». Estas palabras del «alatristemente célebre productor de best sellers» según el también académico Francisco Rico, fueron replicadas por éste en «Las académicas y los académicos» en la sección Opinión del diario EL PAÍS, de 14 de octubre de 2016. Más recientemente, y ejemplo de estas reticencias, el académico Pérez Reverte ha amenazado con abandonar el sillón T de la RAE si finalmente se revisa la Constitución para adecuarla al lenguaje inclusivo.

${ }^{46}$ Este tipo de medidas - temporales, razonables y proporcionadas- podrían corregir situaciones patentes de desigualdad de hecho respecto de los hombres; a saber: infrarrepresentación de mujeres en Cátedras, Investigadoras Principales en Proyectos Competitivos, Altos Tribunales (TC, TS, Presidencia de Tribunales), Reales Academias, entre un largo etcétera que incluye la infarrepresentación de mujeres en sectores tradicionalmente considerados como masculinos. En esta línea, el Ayuntamiento de Valencia ha previsto la modificación de su Plan de Igualdad para 2017 contemplando acciones positivas para la contratación de mujeres en los puestos de trabajo municipales donde se encuentren infrarrepresentadas, como los de Policía Local y Bomberos, y cuya presencia se eleva apenas a un 12,3\% de la plantilla, en el conjunto del área de Protección Ciudadana. 
actual tejido empresarial ${ }^{47}$, descontando autónomos) la conveniencia de apostar por la igualdad efectiva ciudadana porque es — aparte de una cuestión de justicia social—, sencillamente, una buena oportunidad para su empresa.

Éstas son sólo algunas de nuestras propuestas, conscientes de las muchas que quedan en el tintero, y de la importancia de apostar, además, por un nuevo modelo de socialización diferencial que no impulse la asignación — predestinada y subordinada - de esferas (doméstica-privada y pública) ni la imposibilidad de saltar de una a otra, sin abandonos ni penalizaciones. No sólo las instancias productivas (mercado y propiedad), y las formales-representativas (procesos judiciales y parlamentos) forman parte del «sistema público de reglas que definen cargos y posiciones con sus derechos y deberes, poderes e inmunidades» ${ }^{48}$. Sabemos de la importancia de la asignación «encubierta» de papeles desde las instituciones socializadoras, asignando una definición social de los sexos.

Sólo redenifiniendo el modelo de ciudadanía ${ }^{49}$ — completa y compleja- - y apostando por el paradigma de justicia del «reconocimiento» que parte del «fundamento de que los demás son como uno mismo y que nada que uno se conceda a sí mismo tiene derecho moral a no concedérselo a otro, sino que, al contrario tiene el deber de pensar en el otro como en un sí mismo» ${ }^{50}$, conseguiremos un modelo de Estado y de democracia que afronte y resuelva el dualismo vital y extinga, por fin, la brecha ciudadana.

\section{BIBLIOGRAFÍA}

Astola Madariaga, J. (2008), «Las mujeres y el estado constitucional: un repaso al contenido de los grandes conceptos del Derecho Constitucional», en Astola Madariaga, J (Ed.), Mujeres y Derecho: Pasado y presente. I Congreso multidisciplinar de la Sección de Bizkaia de la Facultad de Derecho, pp. 227-290.

Balaguer Callejón, M.L. (ed.) (2004), XXV Aniversario de la Constitución Española: propuestas de reformas, Málaga: Diputación de Málaga.

Balaguer Callejón, M.L. (2005), «Mujer y derechos constitucionales», en Freixes Sanjuán, T. y Sevilla Merino, J. (Coords.), Género, Constitución y Estatutos de Autonomía, Madrid: INAP, pp. 237-265.

47 Según datos proporcionados por el Ministerio de Empleo y Seguridad Social, correspondientes a enero de 2017, de un total de 2.839.112 empresas, 4262 corresponden a empresas de más de 250 personas trabajadoras.

48 Rawls, J. (1993), Teoría de la Justicia, Madrid, FCE, p. 76.

$49 \mathrm{Al}$ respecto resultan fundamentales las aportaciones teóricas de Rubio CaStro, A. (1997), Feminismo y Ciudadanía, Sevilla, IAM, Estudios 8. Reeditado en 2007, México, UAM; y la publicada en (2006), bajo el título Lo público y lo privado en el contexto de la globalización. Sevilla, Instituto Andaluz de la Mujer, entre otras.

50 Vid. ValCárcel, A. (1993), Del miedo a la igualdad, Barcelona, Crítica, p. 7. 
Barrère UnZueta, M.A. (2003), «Ciudadanía europea e igualdad de género», Revista Vasca de Administración Pública, n. ${ }^{\circ}$ 66, pp. 47-66.

Barrère Unzueta, M.A. (2014), El Derecho Antidiscriminatorio y sus límites, Perú: Grijley.

Ballester Pastor, M.A (2012), «De cómo la reforma operada por el Real Decreto Ley 3/2012 ha degradado el derecho fundamental a la conciliación de responsabilidades», Revista de Derecho Social, n. ${ }^{\circ} 57$, pp. 99 y ss.

Cabeza Pereiro, J. (2012), «La discriminación retributiva por razón de sexo como paradigma de discriminación sistémica», Lan Harremanak/Revista de Relaciones Laborales, n. ${ }^{\circ} 25$.

CASTAÑo, C. (dir.) (2015), Las mujeres en la gran recesión: politicas de austeridad, reformas estructurales y retrocesos en la Igualdad de Oportunidades, Valencia: Cátedra, Colección Feminismos.

Clavero, V. (2017), «Desigualdad. La brecha entre las pensiones de hombres y mujeres se ha ensanchado durante la crisis», PUBLICO, 8 de febrero de 2017.

Esquembre Cerdá, M. (2016), «Las mujeres ante el cambio constitucional. Algunos apuntes desde una perspectiva feminista para una «reforma constituyente» de la Constitución Española», Atlánticas. Revista Internacional de estudios feministas, 1, (1), 184-212.

Facio Montejo, A. (1993), Cuando el Género suena, cambios trae. Una metodología para el análisis del fenómeno jurídico desde la perspectiva de Género, Ilanud.

Facio Montejo, A y Fries, L. (1999), Género y Derecho, Santiago de Chile: LOM Ediciones.

Facio Montejo, A. (2002), «Con los lentes de género se ve otra justicia», Revista El otro Derecho, n. ${ }^{\circ}$ 28, pp. 85-102, Bogotá D.C., Colombia: ILSA

Fernández Prieto, M. y Cabeza Pereiro, J. (ed.) (2012), Políticas de conciliación, permisos parentales y empleo, Albacete: Bomarzo.

Freixes SANJuÁn, T. (2004), «La Igualdad y el futuro de Europa», en BALAguer Callejón, M.L. (Ed.), XXV Aniversario de la Constitución Española: propuestas de reformas, Málaga: Diputación de Málaga, pp. 241-269

Freixes Sanjuán, T. (2005), «La perspectiva de género en la elaboración de la constitución europea», en Freixes Sanjuán, T. y Sevilla Merino, J. (Coords.), Género, Constitución y Estatutos de Autonomía, Madrid: INAP, pp. 69-99.

Freixes Sanjuán, T. y Sevilla Merino, J. (Coords.) (2005), Género, Constitución y Estatutos de Autonomía, Madrid: INAP.

GÁlvez MuÑoz, L. (dir.) (2016), La economía de los cuidados, Sevilla: deculturas.

GiL RuIz, J.M. (2007), Los diferentes rostros de la Violencia de Género, Madrid: Dykinson.

GiL RuIz, J.M. (2012), Las nuevas Técnicas Legislativas en España, Valencia: Tirant lo Blanch.

GiL Ruiz, J.M. (2014a), «La Violencia Institucional de Género», Anales de la Cátedra Francisco Suárez, n. ${ }^{\circ}$ 48, pp. 9-18. 
GiL RuIz, J.M. (2014b), «Introducción de la perspectiva de género en las Titulaciones Jurídicas: hacia una formación reglada», en Revista de Educación y Derecho. Education and Law Review, vol. 10.

GiL RuIz, J.M. (2015), «Formación en Derecho Antidiscriminatorio: carencias e incumplimientos institucionales», Revista ACADEMIA. Revista sobre enseñanza en Derecho, vol. 26, año 13, Argentina, pp. 49-77.

GiL RuIz, J.M. (2017), «Hablemos otra vez de igualdad pero hagamos alguna vez algo de verdad», Huffingthon post, 8 de marzo de 2017. Accesible en https:// www.huffingtonpost.es/juana-maria-gil-ruiz/hablemos-otra-vez-de-igualdadpero-hagamos-alguna-vez-algo-de-v_a_21875471/

Kleven, H. J., LANDAis, C., SogAaRd, J. E. (2017), Children and Gender Inequality: Evidence from Denmark, New York. Accesible en https:/www.henrikkleven.com/ uploads/3/7/3/1/37310663/kleven-landais-sogaard_gender_feb2017.pdf

Lousada Arochena, J.F. (2013), «La reforma laboral en perspectiva de género», XIV Congreso Nacional de Abogados Laboralistas, organizado por la Asociación Nacional de Abogados Laboralistas, A Coruña.

Lousada Arochena, J.F., «La integración de la perspectiva de género en la aplicación e interpretación de las normas por la jurisdicción social», Revista de Derecho Social, 2016, n. ${ }^{\circ}$ 76, pp. 39-58

Marrades, A. (2016), «Los nuevos derechos sociales: el derecho al cuidado como fundamento del Pacto Social», en Revista de Derecho Político, n. ${ }^{\circ} 97$, pp. 209-242.

Pazos PÉrez, A. (2012), «La reducción de jornada tras las últimas reformas legislativas», en Fernández Prieto, M. y Cabeza Pereiro, J. (ed.), Políticas de conciliación, permisos parentales y empleo, Albacete: Bomarzo, pp. 242 y ss.

Rawls, J. (1993), Teoría de la Justicia, Madrid: FCE.

Rey-Martínez, F. (2004), «Comentario a los informes del Consejo de Estado sobre el impacto por razón de género», Teoría y realidad constitucional, n. ${ }^{\circ} 14$, pp. 500523.

Ron Latas, R.P. (2013), «Comentario a la Sentencia del Tribunal Constitucional 61/2013, de 14 de marzo, sobre la cuestión de constitucionalidad sobre pensiones de jubilación para trabajadores a tiempo parcial», Revista Aequalitas, n. ${ }^{\circ} 32$.

Rubio Castro, A. (1997), Feminismo y Ciudadanía, Sevilla: IAM, Estudios 8. Reeditado en 2007, México: UAM.

Rubio Castro, A. (2006), Lo público y lo privado en el contexto de la globalización. Sevilla: Instituto Andaluz de la Mujer.

SAlazar Benítez, O. (2015), «Ciudadanía, género y poder: la paridad como principio constitucional», en Cuestiones de género: de la igualdad y la diferencia, n. ${ }^{\circ} 10$ : pp.16-37.

STANG Dahl, T. (1986), «Building Women's Law», International Journal of the Sociology of Law, 14/3-4.

VAlCÁrcel, A. (1993), Del miedo a la igualdad, Barcelona: Crítica. 
Title:

Rethinking the Spanish Constitution: a look at the duty to work and the right to work

\title{
Summary:
}

1. A review of The Constitution of 1978 in the face of the new international juridical impulses. 2. European and national protection based on gender: a look at the Right to Work. 3. The persistence of the gender gap and the urgency of a constitutional response. 4. Some concluding proposals and of legal and political improvement.

\section{Resumen:}

Han pasado cuarenta años desde que se aprobara la Constitución española y veintitrés desde que España ratificara la Declaración y la Plataforma de Acción de la IV Conferencia Mundial sobre la Mujer de Beijing (1995). Esta última supuso el compromiso de incorporación del principio del gender mainstreaming en la totalidad de los procesos normativos —elaboración, interpretación y aplicación de la normasy en la totalidad de las políticas públicas. Y esta misma fecha debiera indicar, en consecuencia, un antes y un después en el hacer jurídico y político.

Este compromiso vinculante compele a revisar la Constitución e incorporar la perspectiva de género de manera principal y transversal, desde el Preámbulo (donde se blindaría) hasta su parte dispositiva. Este trabajo se centra especialmente en el artículo 35 y en su proclama referida al deber y al derecho al trabajo, habida cuenta de que la brecha salarial, la necesidad de reequilibrar la vida laboral, familiar y personal y la necesidad de combatir todas las formas de violencia contra las mujeres, se erigen entre los grandes desafíos ciudadanos del siglo xxI.

\begin{abstract}
:
Forty years have passed since the Spanish Constitution was approved and twenty-three years since Spain ratified the Declaration and Platform for Action of the Fourth World Conference on Women in Beijing (1995). The latter entailed a commitment to incorporate the principle of gender mainstreaming in all the regulatory processes —elaboration, interpretation and application of standards - and in all public policies and this very same date should mark a before and after in both legal and political matters.

This binding commitment compels to review the Constitution and incorporate the gender perspective in a main and transversal way, from the Preamble (where it would be shielded) to its operative part. This work focuses especially on article 35 to the recognition of the duty and the right to work, given that challenges such as the gender wage gap, the
\end{abstract}


need to rebalance work, family and personal life and the need to combat all forms of violence against women, stand among the greatest ones of the XXI century.

Palabras clave:

Constitución Española; gender mainstreaming; derecho del trabajo; brecha salarial; conciliación de la vida familiar, laboral y personal.

\section{Key words:}

Spanish Constitution; gender mainstreaming; labor law; wage gap; reconciliation of family, work and personal life. 